\title{
Gestión de la ganadería y patrones de consumo de una comunidad indígena expuesta al fenómeno colonial: el caso de la Estructura 12 de la Cueva Pintada (Gran Canaria, España)
}

\author{
PABLO CASTELLANO-ALONSO ${ }^{1}$, MARTA MORENO-GARCÍA ${ }^{2}$, \\ AMELIA RODRÍGUEZ RODRÍGUEZ ${ }^{1}$, JOSÉ IGNACIO SÁENZ SAGASTI ${ }^{3}$ \& \\ JORGE ONRUBIA PINTADO ${ }^{4}$
}

\author{
${ }^{1}$ Grupo de Investigación TARHA, Departamento de Ciencias Históricas, Universidad de Las Palmas de Gran Canaria \\ pcastellanoalonso@gmail.com \\ ${ }^{2}$ Instituto de Historia-CSIC, Madrid \\ ${ }^{3}$ Museo y Parque Arqueológico Cueva Pintada-Cabildo de Gran Canaria, Gáldar \\ ${ }^{4}$ Laboratorio de Arqueología, Patrimonio y Tecnologías Emergentes (IDR), Universidad de Castilla La Mancha, \\ Ciudad Real
}

(Recibido 5 junio 2017; Revisado 27 julio 2017; Aceptado 8 septiembre 2017)

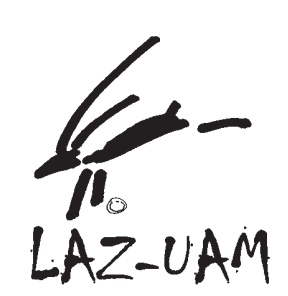

RESUMEN: Se presenta el estudio de los taxones faunísticos domésticos recuperados en dos contextos espaciales y estratigráficos documentados en la Estructura 12 del yacimiento de La Cueva Pintada de Gáldar (Gran Canaria, España). Datados entre los siglos XV y XVI d.C., uno es indiscutiblemente anterior a la conquista de la isla y el otro corresponde, con toda probabilidad, a un momento en el que esta ya se ha producido.

Cerdos, cabras y ovejas son las únicas especies domésticas consumidas durante todo el siglo XV y principios del siglo XVI. No se documentó la introducción de nuevos animales ni se detectó el uso de herramientas metálicas para el tratamiento carnicero o el consumo. Sin embargo, en el contexto más antiguo de los analizados, previo a la anexión definitiva de la isla, la frecuencia de restos de cerdo $(\mathrm{NME}=63 \%$ ) es muy superior a la de caprinos $(\mathrm{NME}=37 \%)$, circunstancia prácticamente inédita en el Archipiélago hasta la fecha. Dicha tendencia parece que se invierte a medida que nos acercamos a finales del siglo XV, periodo de plena ocupación colonial. Lo que permanece inalterable es la mayor proporción de cabras con respecto a las ovejas en cada etapa. Los perfiles de mortalidad a lo largo de la secuencia estudiada sugieren que mientras cabras y ovejas eran consumidas a cualquier edad durante todo el año, aunque preferentemente adultas, el sacrificio de cerdos se centraba en individuos subadultos, con edades comprendidas entre los 1225 meses, una vez habían alcanzado su peso óptimo. Este resultado muestra el aprovechamiento diversificado de la cabaña caprina y la gestión especializada en el mantenimiento de la cabaña porcina, pudiendo estar su sacrificio asociado a momentos y espacios en los que la demanda de carne fuera mayor.

PALABRAS CLAVE: ARQUEOZOOLOGÍA, PATRONES DE CONSUMO, CRIANZA DE GANADO, CANARIAS PREEUROPEA, PERIODO COLONIAL

ABSTRACT: The archaeozoological study of the domestic livestock recovered from two different stratigraphic contexts, from Structure 12 of the Cueva Pintada of Gáldar site (Gran Canaria, Spain) is presented. Both contexts are dated between the fifteenth and sixteenth centuries CE. One of them is definitely previous to the conquest of the island, while the other belongs to a period in which that conquest had already taken place.

Pigs, goats and sheep are the domestic species consumed during the fifteenth century and the beginning of the sixteenth century. There is no evidence for the introduction of new livestock nor the use of metal tools during butchery or consumption activities. However, in the earlier context, previous to the annexation to the Castilian Crown, pigs abundances $(\mathrm{MNE}=63 \%)$ are much higher than those of caprines (goats and sheep) $(\mathrm{MNE}=37 \%)$, an unparalleled circumstance in the 
Canary Islands thus far. This trend seems to reverse during the last decades of the fifteenth century, coinciding with the period of colonial occupation. The only issue that remains unchanged in every context is the higher proportion of goats versus sheep. Mortality profiles suggest that goats and sheep were consumed at any age throughout the year, although adults were preferred. In contrast, pig slaughtering focused on sub-adults, between 12-25 months old, when pigs reach their optimal weight. These results show that caprines were sacrificed at different ages for different purposes, whereas pig breeding was highly specialised, probably aimed at obtaining the maximum amount of meat at any given time.

KEYWORDS: ARCHAEOZOOLOGY, MEAT CONSUMPTION PATTERNS, HUSBANDRY, PRE-EUROPEAN CANARIES, COLONIAL PERIOD

\section{INTRODUCCIÓN}

Las Islas Canarias se localizan en el Océano Atlántico, a escasos $100 \mathrm{~km}$ de las costas del Sur de Marruecos y del Sáhara. Las siete islas mayores que forman el Archipiélago son Lanzarote, Fuerteventura, Gran Canaria, Tenerife, La Gomera, La Palma y El Hierro. Los datos sobre la primera población que llegó a sus costas coinciden en señalar un origen geográfico situado en algún lugar del Norte de África, en fechas cercanas al cambio de Era (Fregel et al., 2009; Secher et al., 2014, entre otros). A partir del siglo XIV, navegantes de Europa comenzaron a entrar en contacto con la población aborigen en viajes de exploración con objetivos comerciales y evangelizadores. Ya en el siglo XV se produjo el proceso de conquista militar, que se desarrolló de manera progresiva desde 1402 (Lanzarote) hasta 1496 (Tenerife), momento en el que todas las islas quedaron bajo el dominio de la Corona de Castilla.

La isla de Gran Canaria fue conquistada en 1483. Sin embargo, su posición estratégica central en el Archipiélago, así como la fertilidad de su territorio, la convirtieron en objeto de deseo para la colonización desde los inicios de la empresa normanda a comienzos del siglo XV. Las narraciones europeas están repletas de episodios que ilustran esos intentos de conquista, evangelización, comercio o rapiña. Aunque muchos de estos materiales correspondan ya a la fase de repoblación europea e hibridación cultural, no es improbable que algunos de los bienes alóctonos localizados en distintos yacimientos de la isla, como cerámicas comunes o de lujo, vidrios, monedas y metales (Onrubia et al., 1998; Fontugne et al., 1999; González-Marrero et al., 2013), tengan que ver con esta más temprana fase de contactos y conflictos. Sin embargo, se ha explorado muy poco cómo afectó a la población y al territorio canario la introducción de fauna y flora nuevas. Esto concierne tanto a las especies aportadas para establecer o consolidar nuevas prácticas agrícolas y ganaderas, como a aquellas otras acompañantes no deseadas, como las malas hierbas, los parásitos o los animales comensales (Atoche, 2003; Morales et al., 2009; Morales, 2010).

Los primeros datos al respecto se recogen, como no podía ser de otra forma, en la documentación escrita, a la que recientemente los estudios arqueobotánicos han añadido nuevas informaciones. Sin embargo, los análisis arqueozoológicos sobre fauna doméstica terrestre han sido menos elocuentes. Se cuenta con datos sobre una decena de yacimientos arqueológicos en los que arqueozoólogos o biólogos han realizado algunas aproximaciones a conjuntos de fauna de muy diversas entidades y cronologías (Zeuner, 1959; Martín-Rodríguez et al., 2003a, 2003b; Ascanio et al., 2004; Velasco \& Alberto, 2005; Rodríguez et al., 2008; Schlueter, 2009; Arco, 2011; Castellano-Alonso, 2013; Castellano-Alonso et al., 2016). En ellos se ofrecen datos que muestran la gran variedad de campos por explorar sobre la sociedad canaria pretérita a partir de la investigación arqueozoológica. Esas primeras aproximaciones nos han mostrado la potencialidad que este registro tiene para responder a una serie de cuestiones u objetivos, que podrían resumirse en: 1) Determinar los hábitos de consumo de los recursos cárnicos; 2) Analizar la producción y los modos de gestión ganadera; 3) Indagar sobre la evolución diacrónica de esas prácticas; y 4) Incidir sobre la naturaleza que tuvo el contacto con las poblaciones europeas que frecuentaban la isla desde el siglo XIV d.C.

Puede señalarse que no solo el número de estudios sobre fauna doméstica ha sido escaso en Ca- 
narias, sino que las muestras identificadas no son cuantitativamente muy elevadas, debido a problemas de conservación, principalmente. A nivel tafonómico, se ha observado un índice de fragmentación intenso en todo el archipiélago, justificado por algunos investigadores (Pais, 1996; Arco, 2011) como un procesado exhaustivo de las carcasas en busca del tuétano. Por tal motivo, es habitual encontrar repertorios con altas tasas de indeterminados, dada la extrema dificultad en identificar fragmentos inferiores a uno o dos centímetros en muchos casos. Se puede afirmar que el conjunto óseo aquí estudiado es de los mejor conservados de Gran Canaria, dando lugar a la identificación de más de 2000 restos óseos.

\section{DESCRIPCIÓN DEL CONTEXTO ARQUEOLÓGICO Y CRONOESTRATIGRAFÍA}

Hemos seleccionado la denominada Estructura 12 del yacimiento arqueológico de la Cueva Pintada (T.M. de Gáldar), cerca de la costa norte de la isla de Gran Canaria (Figura 1), para tratar de dar respuesta a alguno de los interrogantes planteados. Los restos que hoy se localizan en este conjunto pertenecieron en su día al amplio asentamiento aborigen de Agaldar, citado por diversas fuentes escritas de los siglos XIV al XVI (Onrubia, 2003). Los datos disponibles permiten considerar que este sector que engloba a la célebre Cueva Pintada era un caserío, un barrio más de los que habrían conformado, en una organización típicamente celular, el asentamiento en su conjunto. Hasta el momento, en ese caserío se han localizado un total de 60 es-

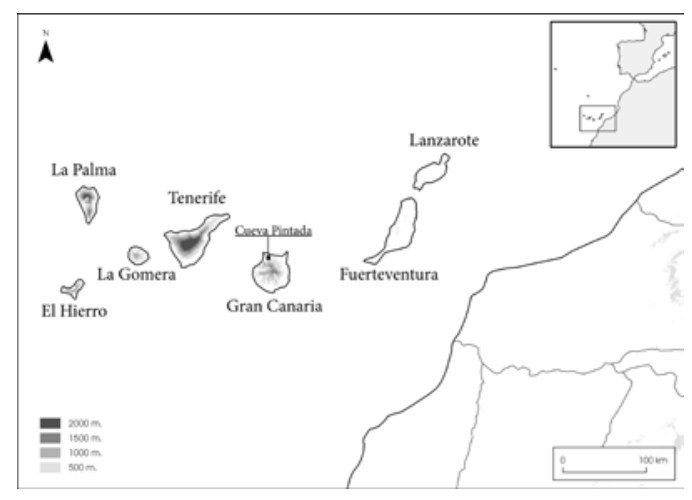

FIGURA 1

Localización de la Cueva Pintada en Gran Canaria (Islas Canarias, España). tructuras domésticas (Figura 2), para las que se han propuesto tres funcionalidades distintas, tomando como base su morfología: espacios de habitación, de cocina y de almacenamiento (Martín et al., 1996; Onrubia, 2012).

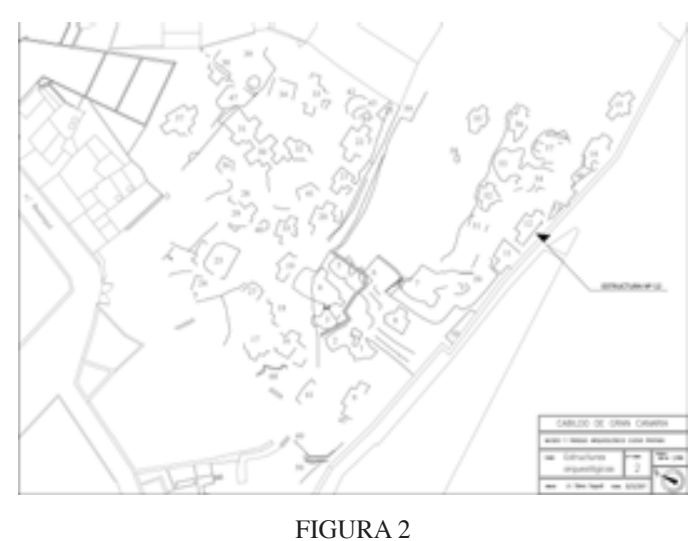

Plano del yacimiento de la Cueva Pintada y ubicación de la Estructura 12. (Imagen: Museo y Parque Arqueológico Cueva Pintada).

Su construcción y uso se secuencia en dos claros momentos de ocupación: un primer asentamiento, cuya cronología se sitúa entre los siglos VII y XI, y una segunda fase, caracterizada por una intensa actividad constructiva y una profunda alteración en la concepción y organización del espacio doméstico, cuyo inicio se data de manera tentativa en el siglo XIII y cuyo final llega, con total seguridad, a los primeros años del XVI. Las numerosas evidencias de niveles de incendio y la reiteración y ubicuidad de depósitos primarios caracterizados por materiales abandonados in situ, podrían interpretarse, con bastante probabilidad, como las pruebas arqueológicas de un episodio de deserción repentina del más antiguo asentamiento (Onrubia, 2003, 2012).

La estructura seleccionada (Figura 3), exhumada en el trascurso de cinco campañas de excavación desarrolladas entre 1990 y 2016, se presenta como idónea, dado que cuenta con dos contextos arqueológicos bien diferenciados y documentados que se suceden, además, en un lapso de tiempo relativamente corto, que incluye todo el siglo XV y principios del XVI. Se trata de una característica habitación de planta interior cruciforme construida sobre el vano de acceso a una pequeña cámara rupestre, correspondiente a una fase de ocupación anterior (Martín et al., 1994, 1996; Fontugne et al., 1999). 
Tanto la pieza central de esta casa como las dos alcobas laterales han sido levantadas con un aparejo mixto constituido por mampuestos de basalto y cantos de toba. Su suelo presenta un pavimento de tierra apisonada que acredita una sucesión de acondicionamientos. El último es una delgada capa, de espesor centimétrico, constituida por la aplicación de un mortero blanquecino (C.E. II, nivel 3 / UE 13), en apariencia muy rico en calcita. Este suelo está fosilizado por los depósitos correspondientes al momento de abandono y arruinamiento de la vivienda (C.E. II, nivel 2).

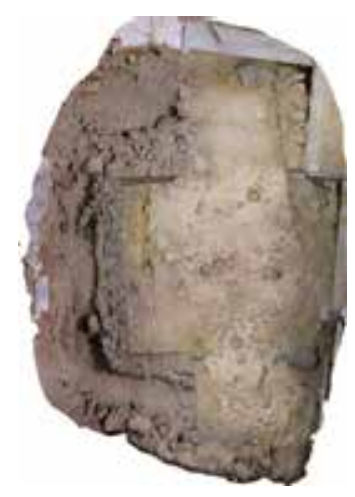

FIGURA 3

Ortofoto de la Estructura 12, donde se vislumbra una pequeña oquedad que corresponde al acceso a la cámara rupestre sellada, en la alcoba Este (margen superior derecha). (Fotografía: Museo y Parque Arqueológico Cueva Pintada).

Sobre el nivel 3 (C.E. II) / UE 13), y formando también parte de su matriz y de sus niveles de preparación, se ha recuperado un abundante material arqueológico in situ. Del desmantelamiento de este depósito primario procede asimismo una parte de los objetos que han sido hallados en los sedimentos de colmatación (C.E. II, nivel 4) que fosilizan el relleno más antiguo (C.E. II, nivel 5 / UEs 5 y 8) de la pequeña cámara rupestre a la que acabamos de aludir. El conjunto de este material presenta una evidente homogeneidad. En él menudean las series indígenas y los objetos coloniales. De este material de importación, marcadamente diagnóstico y entre el que destaca una blanca de rombo de Enrique IV (González-Marrero et al., 2013) y un fragmento de tafetán de cáñamo que ha podido ser datado por C14 (Beta-321399; fecha radiocarbónica convencional: $350 \pm 50 \mathrm{BP}$; fecha calibrada $(2 \sigma)$ : cal AD 1450 a 1640), puede deducirse que esta vivienda parece haber servido por última vez como espacio de habitación entre las últimas décadas del siglo $\mathrm{XV}$ y las primeras del XVI.

El acondicionamiento de la cámara rupestre, que supera los $3 \mathrm{~m}$ de largo, por una anchura cercana a los 2,5 $\mathrm{m}$ y una altura máxima de $1,6 \mathrm{~m}$, es sin duda anterior (Figura 4). Las dataciones absolutas disponibles sitúan su excavación, o al menos el llagueado con mortero de algunas de sus fisuras, entre los siglos VII a IX, es decir, dentro de la primera fase de ocupación del poblado (datación sobre carbones de laurácea: SacA 42506 / Gif-13157; fecha radiocarbónica convencional: $1260 \pm 30 \mathrm{BP}$; fecha calibrada (20): cal AD 669 a 865).

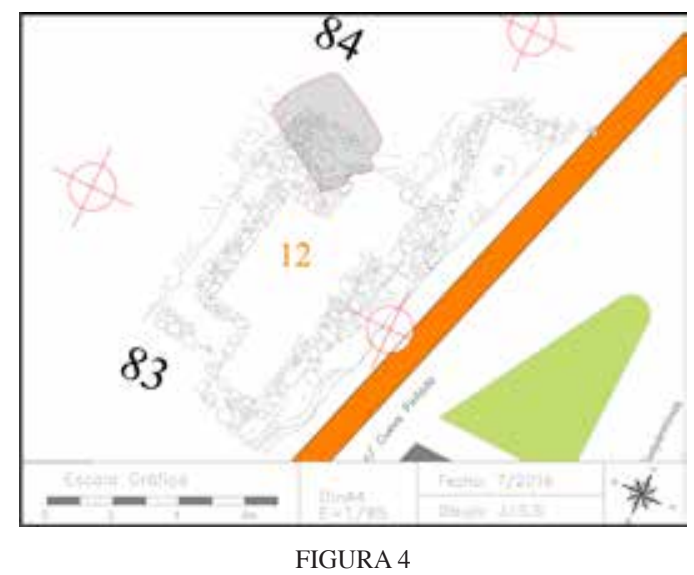

Estructura 12, con la cámara rupestre anexa a la alcoba lateral Este. (Imagen: Museo y Parque Arqueológico Cueva Pintada).

Sobre el piso de la cavidad descansa un paquete arqueosedimentario (C.E. II, nivel 5 / UEs 5 y 8) desplazado y removilizado, como acredita la composición, disposición y fragmentación del material, y su concentración diferencial en determinadas zonas de la cavidad. Las series de artefactos recuperados presentan, sin embargo, una composición homogénea destacando, de manera significativa, la ausencia de objetos coloniales. Su cronología, establecida a partir de la datación de un fragmento de hueso de caprino, se sitúa en la primera mitad del siglo XV (Beta-421926. Fecha radiocarbónica convencional: $510 \pm 30$ BP. Fecha calibrada $(2 \sigma)$ : cal AD 1400 a 1440). El techo de este paquete está parcialmente alterado por el depósito que lo fosiliza (C.E. II, nivel 4) cuya génesis está al menos parcialmente vinculada, como ya hemos visto, con el desmantelamiento de los muros y los pavimentos funcionales de la casa anexa. La disposición y el buzamiento de este nivel geoarqueológico no ex- 
cluyen, no obstante, que una parte de sus sedimentos y materiales procedan de la alteración, removilización y deposición de superficies arqueológicas situadas en cotas superiores.

Si la relación de anterioridad / posterioridad de la casa y de la cueva anexa no ofrecen duda alguna, sus respectivas secuencias de uso y su eventual vinculación funcional están, en cambio, pendientes de determinar con el suficiente detalle. Todo apunta a pensar, con todo, que durante el último episodio funcional de la vivienda aparejada con muros de piedra, el acceso a la cueva se encontraba condenado bajo el pavimento y el paño norte de la alcoba derecha de la habitación. Y según se desprende de las características y materiales de las UEs 27 y 28 documentadas durante el decapado de esta alcoba, es probable que exista una relación entre estos depósitos sedimentarios y el relleno basal de la cavidad. Queda por determinar, con la debida precisión y robustez, la exacta génesis del conjunto de los mismos y su correcta inserción en la secuencia de uso y amortización de los espacios arqueológicos a los que se asocian, singularmente en todo lo relacionado con el proceso de acondicionamiento de la estructura de piedra.

\section{MATERIAL FAUNÍSTICO Y MÉTODOS}

Los restos faunísticos estudiados se vinculan a tres contextos espaciales de la Estructura 12 que fueron recuperados en las campañas de 1993 y 1995: a) la alcoba lateral Este, único espacio del interior de dicha estructura de época colonial completamente excavado y estudiado durante las campañas previas al nuevo programa de intervenciones que se está desarrollando desde 2013, que comprende los niveles 2 y 3 (C.E.II); b) el relleno de colmatación y amortización de la cueva anexa a la alcoba, que corresponde al nivel 4 (C.E.II); c) y por último, el depósito basal del interior de la cueva, el nivel 5 (C.E.II), contexto precolonial cuya naturaleza, como se ha indicado arriba, está por precisar.

La identificación anatómica y taxonómica se ha llevado a cabo mediante la consulta de la colección de referencia de la Universidad de Las Palmas de Gran Canaria y del laboratorio de Arqueobiología del Instituto de Historia, CCHS-CSIC de Madrid, así como de atlas y manuales específicos (Boessneck et al., 1964; Schmid, 1972; Barone, 1976). Bajo el término "OC" o "caprino" se agrupan los restos determinados de cabras, ovejas y aquellos que no se han podido identificar a nivel específico, dada la dificultad que entraña tal distinción en muchas ocasiones (Boessneck et al., 1964). Entre los restos no determinados se distinguen dos categorías: 1) Mamífero de talla media, agrupando fragmentos de costillas, vértebras, cráneo y huesos largos de mesomamíferos, como son cabras, ovejas, cerdos y perros, que por falta de caracteres diagnósticos no fueron identificados taxonómicamente. Si bien no se ha reconocido ningún resto de perro en la muestra analizada, sí se observaron huesos con mordeduras e impresiones de sus dientes que sugieren la presencia de esta especie en el asentamiento; 2) Sin identificar: pequeñas esquirlas sin características anatómicas o taxonómicas reconocibles.

Se han registrado todos los restos recuperados, tanto determinados como no determinados (Grayson, 1984). La cuantificación de las frecuencias taxonómicas se realiza con los especímenes identificados (NISP). Pero, con el objetivo de no sobre-representar aquellas especies con mayor número de elementos esqueléticos (en nuestro caso el cerdo frente a los caprinos), o que pudieran estar más fragmentadas, hemos calculado el número mínimo de elementos (NME) recuperado para cada especie a partir de la cuantificación de las zonas diagnósticas (Moreno-García et al., 1996) que no se repiten en cada uno de los huesos que conforman el esqueleto. Además, se ha ponderado el número de metápodos y falanges de cerdo en relación a los de caprinos y en esta cuantificación no se han considerado los incisivos, caninos, primeros premolares y las fíbulas de cerdo, así como los cuernos y los incisivos de los caprinos. De este modo, los valores corregidos que se presentan con el NME resultan más adecuados para comparar entre especies. Y por el mismo motivo, el NME es generalmente inferior al NR.

A pesar de ser conscientes de las limitaciones del método del número mínimo de individuos (NMI) y de su artificialidad, lo hemos introducido para comparar sus resultados con los del NME. Su cálculo se realiza considerando el hueso o el diente más frecuente de cada especie por nivel, teniendo en cuenta la lateralidad, la edad y su constitución, además de las zonas diagnósticas presentes en cada elemento.

La determinación de la edad de sacrificio de las cabañas porcina y caprina se ha realizado a partir del registro de los estadios de fusión epifisaria de 
los huesos del esqueleto apendicular (Silver, 1969; Zeder, 2006) y del análisis de la erupción de la dentición permanente y el desgaste de las superficies de oclusión de los dientes inferiores (Payne, 1973, 1987; Grant, 1982; O'Connor, 1988, 2003; Lemoine et al., 2014). Se han empleado tanto mandíbulas izquierdas como derechas, descartando aquellas susceptibles de pertenecer al mismo individuo, considerando para ello que tuvieran el mismo estado de desgaste mandibular (MWS) y que se localizaran en un mismo espacio dentro de un levantamiento concreto. Entre los dientes sueltos únicamente se han utilizado los cuartos premolares deciduos (dLP4) y los terceros molares inferiores (LM3), dado que, por sí mismos, son indicadores bastante fiables de la edad de los individuos. En el caso de los cerdos, hemos creído conveniente dotar de una edad estimada a cada una de las categorías descritas por O'Connor (O'Connor, 1988), con el fin de poder comparar las edades de sacrificio de suidos y caprinos. Para ello, se han observado las edades de erupción de la dentición mandibular propuestas por diversos investigadores (véase un compendio en Legge, 2013; Lemoine et al., 2014) obteniendo la secuencia recogida en la Tabla 1.

La representación de las partes anatómicas se ha estimado a partir del NME. Distinguimos cinco regiones anatómicas que resultan comparables entre sí al haberse ponderado el valor de los elementos que las integran (Tabla 2) (O’Connor, 2003).

\section{RESULTADOS}

\section{Caracterización de las muestras}

El material recuperado comprende 6361 restos de mamíferos (Tabla 3) y 10 de aves, a los que se suma herpetofauna, ictiofauna y malacofauna, estudiada o en proceso de estudio por otros investigadores, y un resto de cetáceo correspondiente a un elemento trabajado, que probablemente evidencia el aprovechamiento puntual de un espécimen varado en la costa, sin relación con las prácticas de pesca vinculadas a la ictiofauna del yacimiento (Rodríguez, 1996). El único taxón salvaje identificado es el conejo, especie no autóctona de la fauna insular. El mayor número proviene de los lechos más profundos (levantamientos 15 y 16) del nivel 4 (C.E. II), mientras su presencia en el nivel 5 (C.E. II) queda restringida a los lechos superiores (levantamientos 17 y 18). La ausencia de alteraciones antrópicas en los restos, junto al aspecto blanquecino y la recuperación de esqueletos parciales sugieren que se trata de intrusiones posteriores al uso de estos espacios durante las épocas aborigen y colonial. La explicación más factible es que en un momento más reciente estos pequeños lagomorfos excavaran madrigueras y algunos quedaran presos en ellas.

En general, la baja contribución de la fracción determinada (39\%) respecto a la indeterminada refleja el alto índice de fragmentación sufrido por la

\begin{tabular}{|ll|}
\hline$<1$ mes & -Neonato: dLP4 sin erupcionar o en proceso de erupción. \\
\hline $1-6$ meses & -Juvenil: dLP4 en desgaste, LM1 sin desgaste. \\
\hline 6-12 meses & -Inmaduro: LM1 en desgaste, LM2 sin desgaste. \\
\hline $12-25$ meses & -Subadulto: LM2 en desgaste, LM3 sin desgaste. \\
\hline$>25<48$ meses & -Adulto: LM3 en desgaste, pero no con desgaste severo. \\
\hline$>48$ meses & -Senil: exposición de la dentina del LM3 en el estadio “j” o posterior (Grant, 1982) \\
\hline
\end{tabular}

TABLA 1

Estimación de la edad en meses de las distintas categorías propuestas por O’Connor (1988).

\begin{tabular}{|ll|}
\hline Región & Elementos \\
\hline Cráneo & Mandíbula; premolares y molares superiores e inferiores \\
\hline Vértebras & Atlas; Axis \\
\hline Cuarto Delantero & Escápula; Húmero proximal+distal; Radio proximal+distal; Ulna proximal; Metacarpo proximal+distal \\
\hline Cuarto Trasero & Pelvis; Fémur proximal+distal; Tibia proximal+distal; Calcáneo, Astrágalo; Metatarso proximal+distal \\
\hline Pezuñas & Primera falange; Segunda Falange; Tercera Falange \\
\hline
\end{tabular}

TABLA 2

Elementos incluidos en cada región anatómica. 


\begin{tabular}{|c|c|c|c|c|c|c|}
\hline \multirow[b]{3}{*}{ Taxa } & \multirow{2}{*}{\multicolumn{2}{|c|}{$\begin{array}{l}\text { Alcoba Este } \\
\text { Niveles 2-3 }\end{array}$}} & \multicolumn{4}{|c|}{ Cámara rupestre } \\
\hline & & & \multicolumn{2}{|c|}{ Nivel 4} & \multicolumn{2}{|c|}{ Nivel 5} \\
\hline & NR & $\%$ & NR & $\%$ & NR & $\%$ \\
\hline \multicolumn{7}{|l|}{ Domésticos } \\
\hline Oveja/Cabra & 108 & 13 & 221 & 18 & 581 & 13 \\
\hline [Oveja] & [1] & & [4] & & {$[21]$} & \\
\hline [Cabra] & [9] & & {$[26]$} & & {$[121]$} & \\
\hline Cerdo & 66 & 8 & 228 & 19 & 1149 & 27 \\
\hline Subtotal & 174 & 21 & 449 & 37 & 1730 & 40 \\
\hline \multicolumn{7}{|l|}{ Salvajes } \\
\hline Conejo & 33 & 4 & 171 & 14 & 73 & 2 \\
\hline Subtotal & 33 & 4 & 171 & 14 & 73 & 2 \\
\hline \multicolumn{7}{|l|}{ No Identificados } \\
\hline Mamífero Talla Media & 227 & 28 & 384 & 31 & 1262 & 29 \\
\hline Sin identificar & 383 & 47 & 216 & 18 & 1259 & 29 \\
\hline Subtotal & 610 & 75 & 600 & 49 & 2521 & 58 \\
\hline Total analizado & 817 & 100 & 1220 & 100 & 4324 & 100 \\
\hline
\end{tabular}

TABLA 3

Relación del número de restos (NR) por taxones y categorías no determinadas. Oveja/Cabra incluye el total de restos de caprinos, ovejas y cabras.

asociación. Por niveles y espacios, se aprecia sin embargo que la muestra peor conservada y menos significativa en términos cuantitativos es la de la alcoba Este, mientras que la procedente del depósito basal (C.E. II, nivel 5) de la cámara rupestre bajo el pavimento de la vivienda es la mejor preservada y con más fauna doméstica. El nivel 4 (C.E. II), correspondiente al estrato de colmatación de esta cavidad y cuyos materiales se relacionan en parte con el desmantelamiento del suelo de ocupación de la Estructura 12, está en una posición intermedia. Es decir, tanto el número de restos recuperado, como la fracción determinada, disminuyen desde el nivel más antiguo (correspondiente a la primera mitad del siglo XV) hasta el más reciente (últimas décadas del XV, principios del XVI). Esto condiciona ciertamente la validez de las muestras de los niveles 2-3 (C.E. II) de la alcoba Este (NISP=174) y del nivel 4 (C.E. II) (NISP=449) a la hora de interpretarlas en relación al nivel 5 (C.E. II), que no solo parece corresponder a un depósito primario poco alterado sino que con 1730 restos determinados representa uno de los mayores conjuntos ar- queofaunísticos del Archipiélago, y ciertamente de la isla de Gran Canaria.

Las alteraciones derivadas de la erosión causada por agentes físico-químicos y naturales (Lyman, 1994) son muy escasas en relación a las producidas por animales comensales, como roedores y perros (Tabla 4). El nivel 5 (C.E. II) es el que presenta una mayor concentración de restos con mordeduras y roídos (67 elementos), si bien estos registros apenas representan el 6\% sobre el total de la muestra.

\section{Cuantificación de las especies domésticas}

Los caprinos y los cerdos son las únicas especies domésticas identificadas. A pesar de las diferencias cuantitativas de las muestras recuperadas en los dos espacios de la Estructura 12 (alcoba Este y cámara rupestre), las frecuencias taxonómicas a lo largo de la secuencia cronológica evidencian un descenso de la presencia de restos cerdo en los ni-

\begin{tabular}{|ccccccc|}
\hline Contexto & NH & Rgw & Dgw & Tthp & E & Ve \\
\hline Alcoba & 123 & $5(4 \%)$ & - & - & $3(2 \%)$ & - \\
\hline Nivel 4 & 331 & $19(6 \%)$ & $1(<1 \%)$ & $1(<1 \%)$ & $3(1 \%)$ & $6(<2 \%)$ \\
\hline Nivel 5 & 917 & $49(5 \%)$ & $12(1 \%)$ & $6(<1 \%)$ & $9(1 \%)$ & $10(1 \%)$ \\
\hline
\end{tabular}

TABLA 4

Relación del número de huesos determinados e indeterminados (NH) con alteraciones (dientes y cuernos excluidos). Rgw: roído por roedores; Dgw: mordido por perros; Tthp: con impacto de dientes; E: erosionado; Ve: muy erosionado. 
veles más recientes (niveles 2-3 de la alcoba este) respecto a los anteriores localizados en la cámara rupestre (Tabla 5). Esta tendencia se verifica tanto por el cálculo porcentual a partir del número de restos (NR) como del NME, una vez corregido y ponderado el sesgo asociado al mayor número de elementos esqueléticos del cerdo, lo que nos permitirá establecer comparaciones con otras muestras del entorno cuyas contribuciones taxonómicas se basan en el NR (vide discusión). De igual forma, el NMI no ofrece valores muy distintos, salvo que las diferencias entre ambas cabañas en el nivel 5 son menores (Tabla 5).

Respecto a la composición de las cabañas caprina y ovina, la relación entre los restos identificados específicamente demuestra el dominio de cabras frente a ovejas (Tabla 6), por lo que es de suponer que una proporción grande de los elementos cuantificados como caprinos pertenezca a cabras. Aunque las muestras de los niveles más recientes son muy reducidas, la tendencia observada sugiere que el consumo de caprinos incluso pudo aumentar con el tiempo (81\%-87\%-89\%, Tabla 6).

\section{Perfiles anatómicos}

Caracterizar la distribución de las diferentes regiones anatómicas por las que se encuentran representadas las cabañas domésticas en los conjuntos analizados resulta de gran interés para establecer la funcionalidad de los espacios en los que se localizan los contextos donde se acumularon los restos faunísticos, así como obtener evidencias relacionadas con el tratamiento y consumo de las carcasas a lo largo del tiempo. En cada una de las muestras se recuperaron elementos de todo el esqueleto de caprinos y cerdos, salvo en la alcoba Este (Figuras 5 y 6). En el nivel basal de la cámara rupestre (C.E. II, nivel 5) los cráneos de caprinos y suidos predominan ampliamente, mientras las otras porciones anatómicas están pobremente representadas, con la excepción de los cuartos delanteros de caprinos que destacan ligeramente por detrás del cráneo.

En el nivel que se sobrepone (C.E. II, nivel 4), además de reducirse mucho el tamaño de la muestra, se aprecian diferencias significativas con respecto al relleno basal. Ahora son el esqueleto axial (los lomos) y en menor medida el cuarto delantero las regiones del cerdo mejor representadas, mientras en los caprinos se observa bastante homogeneidad en la contribución de todas las regiones, con un ligero predominio del cuarto trasero. En ambos taxones, las pezuñas son escasas. Al tratarse de un nivel de amortización es de suponer que una parte de los residuos aquí acumulados tenga un origen mixto y más variado que el del nivel 5 (C.E. II).

Por último, los pocos restos del suelo de ocupación de la alcoba Este no divergen entre caprinos y cerdos. Corresponden fundamentalmente a cuartos delanteros y traseros, tal como sería esperable en un espacio de consumo.

\begin{tabular}{|c|c|c|c|c|c|c|c|c|c|c|c|c|c|c|c|c|c|c|}
\hline & \multicolumn{6}{|c|}{ Alcoba Este } & \multicolumn{12}{|c|}{ Cámara rupestre } \\
\hline & \multicolumn{6}{|c|}{ Niveles 2-3 } & \multicolumn{6}{|c|}{ Nivel 4} & \multicolumn{6}{|c|}{ Nivel 5} \\
\hline Taxón & NR & $\%$ & NME & $\%$ & NMI & $\%$ & NR & $\%$ & NME & $\%$ & NMI & $\%$ & NR & $\%$ & NME & $\%$ & NMI & $\%$ \\
\hline Oveja/Cabra & 108 & 62 & 62 & 61 & 5 & 62,5 & 221 & 49 & 83 & 46 & 3 & 43 & 581 & 34 & 319 & 37 & 14 & 44 \\
\hline [Oveja] & [1] & {$[<1]$} & [1] & {$[1]$} & {$[1]$} & {$[12,5]$} & [4] & {$[<1]$} & [4] & [2] & [1] & [14] & [21] & [1] & [21] & [2] & [3] & [9] \\
\hline [Cabra] & [9] & {$[5]$} & [8] & {$[8]$} & [1] & {$[12,5]$} & [26] & {$[6]$} & [26] & [15] & [2] & [29] & [121] & [7] & [92] & [11] & [10] & [31] \\
\hline Cerdo & 66 & 38 & 39 & 39 & 3 & 37,5 & 228 & 51 & 96 & 54 & 4 & 57 & 1149 & 66 & 553 & 63 & 18 & 56 \\
\hline Total & 174 & 100 & 101 & 100 & 8 & 100 & 449 & 100 & 179 & 100 & 7 & 100 & 1730 & 100 & 872 & 100 & 32 & 100 \\
\hline
\end{tabular}

TABLA 5

Relación y frecuencia de los taxones domésticos según NR: número de restos. NME: número mínimo de elementos y NMI: número mínimo de individuos. Entre corchetes, ovejas y cabras identificados específicamente, ya incluidos en el conjunto de Oveja/Cabra.

\begin{tabular}{|ccc|}
\hline Nivel & \% NME Cabra & \% NME Oveja \\
\hline Nivel 2-3 & 89 & 11 \\
\hline Nivel 4 & 87 & 13 \\
\hline Nivel 5 & 81 & 19 \\
\hline
\end{tabular}

TABLA 6

Porcentajes de cabras y ovejas en cada nivel atendiendo al NME.

\section{Perfiles de mortalidad}

La disparidad numérica entre las muestras impide obtener datos representativos de cambios diacrónicos (desde inicios del siglo XV hasta inicios 


\section{OC Distribución anatómica}

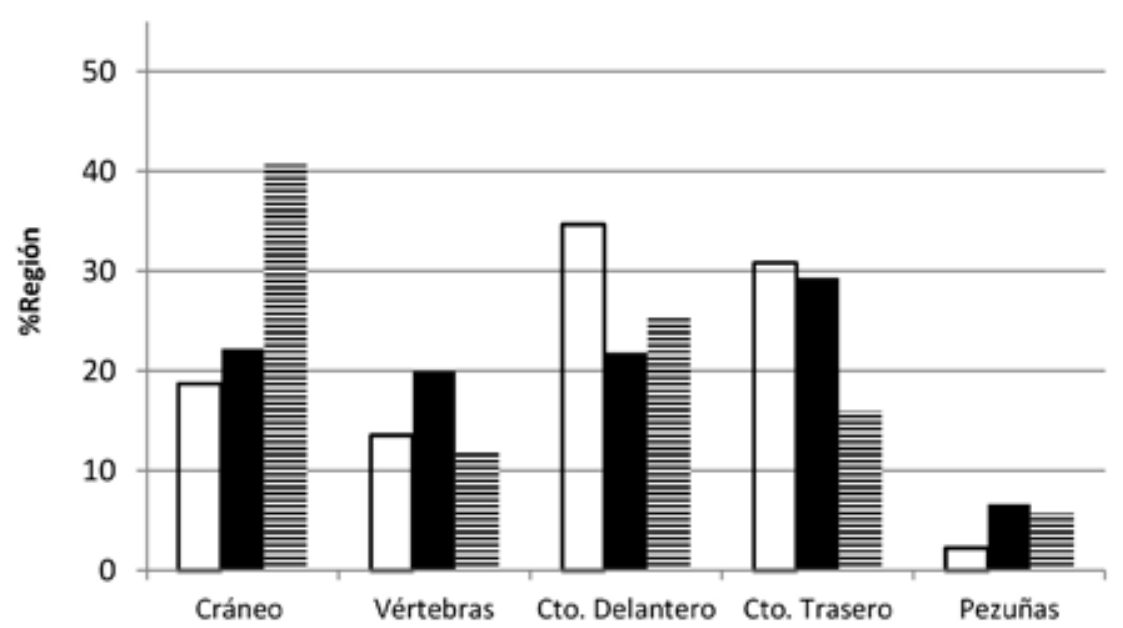

FIGURE 5

Distribución anatómica por regiones del conjunto de caprinos.

\section{SUS Distribución anatómica}

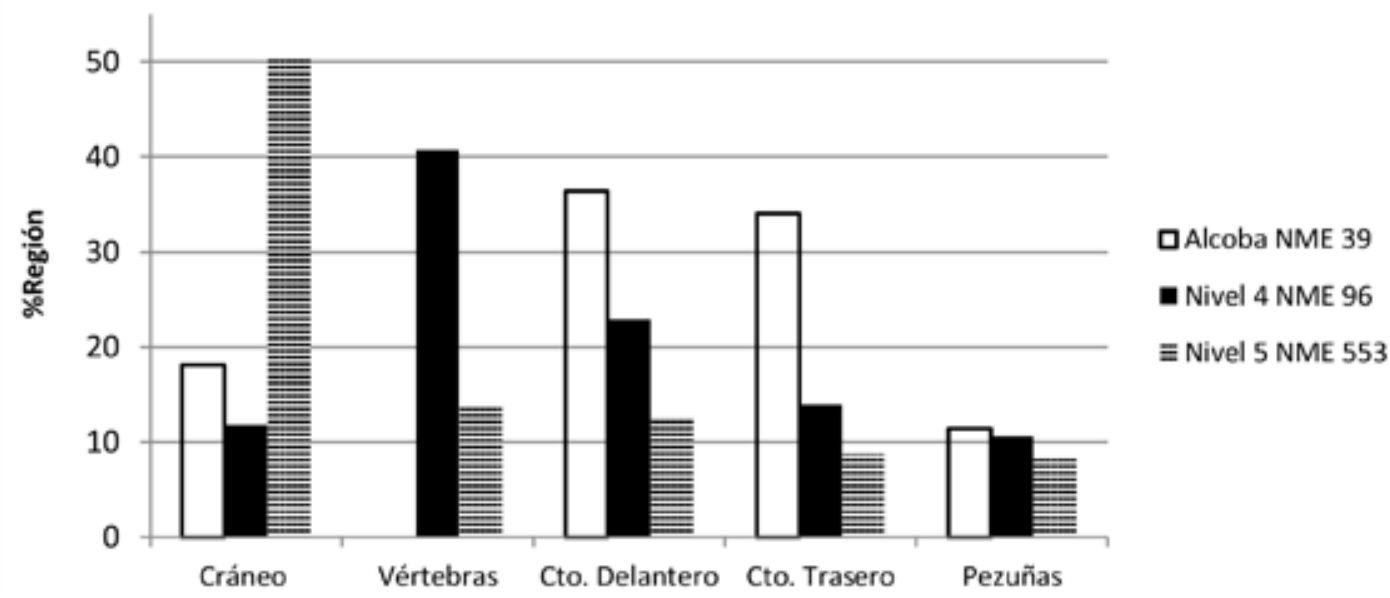

FIGURE 6

Distribución anatómica por regiones de los restos de cerdo.

del XVI) en la gestión y el aprovechamiento de las cabañas ganaderas explotadas por la comunidad humana asentada en el poblado de la Cueva Pintada. Limitamos nuestro análisis a comparar los patrones de sacrificio de caprinos y de cerdos con el objetivo de entender si existían divergencias o semejanzas entre ambos.

Con respecto a los caprinos, los estadios de fusión epifisaria y los desgastes dentales reflejan el sacrificio regular y continuo de todas las cohortes.
Tal patrón es indicativo de una gestión ganadera autosuficiente no especializada únicamente en la producción cárnica. En concreto, la muestra más representativa del nivel 5 permite observar cómo el sacrificio de animales jóvenes y subadultos menores de 4 años está prácticamente igualado con el de individuos adultos ( $\% \mathrm{SF}=46$, Tabla 7; estadios G-I $=45 \%$, Tabla 8). El pico de mortalidad registrado entre los 4-6 años de edad (estadio G; Tabla 8) correspondería al sacrificio de hembras cuya vida 


\begin{tabular}{|c|c|c|c|c|c|c|c|c|c|c|}
\hline \multirow{3}{*}{ Fusión } & \multirow{3}{*}{ Elemento } & \multirow{2}{*}{\multicolumn{3}{|c|}{$\begin{array}{l}\text { Alcoba Este } \\
\text { Niveles 2-3 }\end{array}$}} & \multicolumn{6}{|c|}{ Cámara rupestre } \\
\hline & & & & & \multicolumn{3}{|c|}{ Nivel 4} & \multicolumn{3}{|c|}{ Nivel 5} \\
\hline & & S.F. & F. & $\%$ S.F. & S.F. & F. & $\%$ S.F. & S.F. & F. & $\%$ S.F. \\
\hline \multirow{6}{*}{$\begin{array}{c}\text { Temprana } \\
\text { (nacimiento-18 } \\
\text { meses) }\end{array}$} & Radio p. & 3 & 2 & 60 & - & 1 & 0 & 1 & 7 & 13 \\
\hline & Húmero d. & 4 & - & 100 & 2 & - & 100 & 2 & 5 & 29 \\
\hline & Escápula d. & - & - & - & 2 & 2 & 50 & 3 & 3 & 50 \\
\hline & 2nd falange $\mathrm{p}$. & - & 1 & 0 & - & 1 & 0 & 2 & 1 & 67 \\
\hline & 1st falange $\mathrm{p}$. & - & - & - & - & 4 & 0 & 5 & 7 & 42 \\
\hline & Subtotal & 7 & 3 & 67 & 4 & 8 & 33 & 13 & 23 & 36 \\
\hline \multirow{5}{*}{$\begin{array}{c}\text { Media } \\
\text { (18-30 meses) }\end{array}$} & Tibia d. & - & 2 & 0 & - & 1 & 0 & 2 & 2 & 50 \\
\hline & Metacarpo d. & - & - & - & - & 1 & 0 & 2 & 6 & 25 \\
\hline & Metatarso d. & - & 2 & 0 & - & 2 & 0 & 4 & 4 & 50 \\
\hline & Metápodo d. & - & 1 & 0 & 1 & 4 & 20 & 4 & 1 & 80 \\
\hline & Subtotal & - & 5 & 0 & 1 & 8 & 11 & 12 & 13 & 48 \\
\hline \multirow{9}{*}{$\begin{array}{c}\text { Tardía } \\
(30-48+\text { meses })\end{array}$} & Calcáneo p. & 2 & - & 100 & - & 2 & 0 & - & - & - \\
\hline & Fémur p. & 1 & - & 100 & 2 & 1 & 67 & 2 & 1 & 67 \\
\hline & Fémur d. & 1 & - & 100 & 1 & 2 & 33 & - & - & - \\
\hline & Ulna p. & 1 & - & 100 & 2 & - & 100 & 5 & 2 & 71 \\
\hline & Radio d. & 2 & 2 & 50 & 1 & - & 100 & 2 & 5 & 29 \\
\hline & Tibia p. & - & - & - & 3 & - & 100 & 2 & - & 100 \\
\hline & Húmero $\mathrm{p}$. & 4 & - & 100 & 1 & 1 & 50 & 1 & - & 100 \\
\hline & Subtotal & 11 & 2 & 85 & 10 & 6 & 63 & 12 & 8 & 60 \\
\hline & TOTAL & 18 & 10 & 64 & 15 & 22 & 41 & 37 & 44 & 46 \\
\hline
\end{tabular}

TABLA 7

Fusiones epifisarias de caprinos por contextos (Zeder, 2006). S.F.: Sin Fusionar; F.: Fusionado; \% S.F.: \% Sin Fusionar. p.: proximal; d.: distal.

reproductora estaba agotada, mientras las cohortes más jóvenes incluirían preferentemente machos que proporcionarían la carne de mejor calidad. Por esta razón, no es de extrañar que los pocos restos postcraneales de caprinos recuperados en la alcoba Este, probablemente derivados de consumo doméstico, pertenezcan en mayor proporción a animales jóvenes (total \% SF= 64; Tabla 7).

\begin{tabular}{|cccccccc|}
\hline & & Alcoba Este & \multicolumn{3}{c|}{ Cámara rupestre } \\
\hline \multicolumn{2}{|c}{ Payne (1973) } & \multicolumn{2}{c}{ Niveles 2-3 } & \multicolumn{2}{c|}{ Nivel 4 } & \multicolumn{2}{c|}{ Nivel 5 } \\
\hline MWS & Edad & N & \% & N & \% & N & \% \\
\hline A & 0-2 meses & - & - & - & - & 4 & 22 \\
\hline B & 2-6 meses & - & - & - & - & 1 & 6 \\
\hline C & 6-12 meses & - & - & - & - & 2 & 11 \\
\hline D & 1-2 años & 1 & 33 & - & - & 1 & 6 \\
\hline E & 2-3 años & - & - & 1 & 20 & - & - \\
\hline F & 3-4 años & - & - & - & - & 2 & 11 \\
\hline G & 4-6 años & 2 & 67 & 2 & 40 & 6 & 33 \\
\hline H & 6-8 años & - & - & 1 & 20 & 1 & 6 \\
\hline I & 8-10 años & - & - & 1 & 20 & 1 & 6 \\
\hline Total & & 3 & 100 & 5 & 100 & 18 & 100 \\
\hline
\end{tabular}

TABLA 8

Desgastes dentales de los caprinos de la Estructura 12 por contextos, agrupados en torno a las categorías de edad propuestas por Payne (1973).
Contrariamente, el patrón de sacrificio de los cerdos en todas las muestras refleja una preferencia clara por la cohorte subadulta compuesta por animales de entre 12-25 meses, es decir aquellos que han alcanzado el óptimo cárnico (total \% SF= 79-78-81, Tabla 9 y 80\%-50\%-100\%, Tabla 10). Este resultado sugiere una gestión especializada de la cabaña porcina orientada a la cría y engorde de animales con el fin de obtener los máximos rendimientos en términos cárnicos.

\section{Marcas de carnicería}

El estudio de las marcas de carnicería se encuentra en curso. Los resultados preliminares indican que este tipo de registro es relativamente escaso, con un total de 182 evidencias repartidas entre todos los contextos y todos los elementos, incluyendo tanto los identificados como los no identificados. Incisiones y cortes profundos pueden vincularse bien con un proceso de carnicería primaria, para desmembrar los animales en una primera instancia, bien con actos de preparación culinaria y consumo 


\begin{tabular}{|c|c|c|c|c|c|c|c|c|c|c|}
\hline \multirow{3}{*}{ Fusión } & \multirow{3}{*}{ Elemento } & \multicolumn{3}{|c|}{ Alcoba este } & \multicolumn{6}{|c|}{ Cámara rupestre } \\
\hline & & \multicolumn{3}{|c|}{ Niveles 2-3 } & \multicolumn{3}{|c|}{ Nivel 4} & \multicolumn{3}{|c|}{ Nivel 5} \\
\hline & & S.F. & F. & $\%$ S.F. & S.F. & F. & $\%$ S.F. & S.F. & F. & $\%$ S.F. \\
\hline \multirow{5}{*}{$\begin{array}{l}\text { Temprana } \\
\text { (nacimiento-1 1/2 } \\
\text { años) }\end{array}$} & Escápula d. & - & 1 & 0 & 2 & - & 100 & - & 3 & 0 \\
\hline & Húmero d. & 5 & - & 100 & 4 & 2 & 67 & 1 & 3 & 25 \\
\hline & Radio p. & - & 1 & 0 & 1 & 1 & 50 & - & 1 & 0 \\
\hline & 2nd falange $\mathrm{p}$. & - & - & - & 2 & 8 & 20 & 13 & 21 & 38 \\
\hline & Subtotal & 5 & 2 & 71 & 9 & 11 & 45 & 14 & 28 & 33 \\
\hline \multirow{8}{*}{$\begin{array}{l}\text { Media } \\
\left(11 \frac{1}{2}-21 / 2 \text { años }\right)\end{array}$} & 1st falange $\mathrm{p}$. & 3 & 3 & 50 & 9 & 1 & 90 & 29 & 5 & 85 \\
\hline & Tibia d. & - & - & - & 1 & - & 100 & 6 & - & 100 \\
\hline & Metacarpo d. & - & - & - & 6 & 2 & 75 & 23 & - & 100 \\
\hline & Metatarso d. & 2 & - & 100 & 7 & - & 100 & 14 & - & 100 \\
\hline & Metápodo d. & 2 & - & 100 & 4 & - & 100 & 22 & 1 & 96 \\
\hline & Calcáneo p. & 2 & - & 100 & 1 & - & 100 & 4 & - & 100 \\
\hline & Fíbula d. & - & - & - & 2 & - & 100 & 4 & - & 100 \\
\hline & Subtotal & 9 & 3 & 75 & 30 & 3 & 91 & 102 & 6 & 94 \\
\hline \multirow{9}{*}{$\begin{array}{l}\text { Tardía } \\
(2 \text { 1 1/2-3 1/2 años) }\end{array}$} & Húmero p. & 3 & - & 100 & 1 & - & 100 & - & - & - \\
\hline & Radio d. & 1 & - & 100 & 5 & - & 100 & - & - & - \\
\hline & Ulna p. & 2 & - & 100 & 2 & - & 100 & 4 & - & 100 \\
\hline & Fémur p. & - & - & - & & - & - & 3 & - & 100 \\
\hline & Fémur d. & - & - & - & 2 & - & 100 & 3 & - & 100 \\
\hline & Tibia p. & 1 & - & 100 & - & - & - & 5 & - & 100 \\
\hline & Fíbula p. & - & - & - & - & - & - & 1 & 1 & 50 \\
\hline & Subtotal & 7 & - & 100 & 10 & - & 100 & 16 & 1 & 94 \\
\hline & & 21 & 5 & 81 & 49 & 14 & 78 & 132 & 35 & 79 \\
\hline
\end{tabular}

TABLA 9

Fusiones epifisarias de suidos por contextos (Silver, 1969). S.F.: Sin Fusionar; F.: Fusionado; \% S.F.: \% Sin Fusionar. p.: proximal; d.: distal.

\begin{tabular}{|c|c|c|c|c|c|c|c|}
\hline \multirow{3}{*}{$\begin{array}{c}\text { O'Connor, } 1988 \\
\text { Categoría } \\
\end{array}$} & \multirow{3}{*}{$\begin{array}{l}\text { Legge, 2013. Lemoine et al. } 2014 \\
\text { Edad } \\
\end{array}$} & \multirow{2}{*}{\multicolumn{2}{|c|}{$\begin{array}{l}\text { Alcoba Este } \\
\text { Niveles 2-3 } \\
\end{array}$}} & \multicolumn{4}{|c|}{ Cámara rupestre } \\
\hline & & & & \multicolumn{2}{|c|}{ Nivel 4} & \multicolumn{2}{|c|}{ Nivel 5} \\
\hline & & $\mathbf{N}$ & $\%$ & $\mathbf{N}$ & $\%$ & $\mathbf{N}$ & $\%$ \\
\hline Neonato & $<1$ mes & - & - & - & - & 3 & 10 \\
\hline Juvenil & $1-6$ meses & - & - & - & - & - & - \\
\hline Inmaduro & $6-12$ meses & - & - & - & - & 1 & 3 \\
\hline Subadulto & $12-25$ meses & 1 & 100 & 1 & 50 & 24 & 80 \\
\hline Adulto & $>25<48$ meses & - & - & 1 & 50 & 2 & 7 \\
\hline Senil & $>48$ meses & - & - & - & - & - & - \\
\hline Total & & 1 & 100 & 2 & 100 & 30 & 100 \\
\hline
\end{tabular}

TABLA 10

Desgastes dentales de los cerdos por contextos de la Estructura 12.

(como el fileteado). Las fracturas longitudinales y transversales las asociamos a la búsqueda de unas piezas cárnicas de menores proporciones y a la extracción de la médula ósea. Pero lo que más destaca en todo el conjunto son las fracturas en las mandíbulas de los cerdos localizadas de manera recurrente entre el cuarto premolar y el primer molar (Figura 7), probablemente para acceder al tuétano, sustancia de alto contenido proteínico, alojado en su interior (Blasco, 1992; Pérez, 1992; Seetah, 2006).

\section{DISCUSIÓN}

Todavía es prematuro llegar a propuestas sobre cómo se desarrolló diacrónicamente la interacción de la población nativa canaria y la europea en aspectos tan cotidianos como la gestión de las cabañas ganaderas. Sin embargo, es un reto que hay que empezar a acometer. El registro relacionado con la Estructura 12 del caserío de la Cueva Pintada 


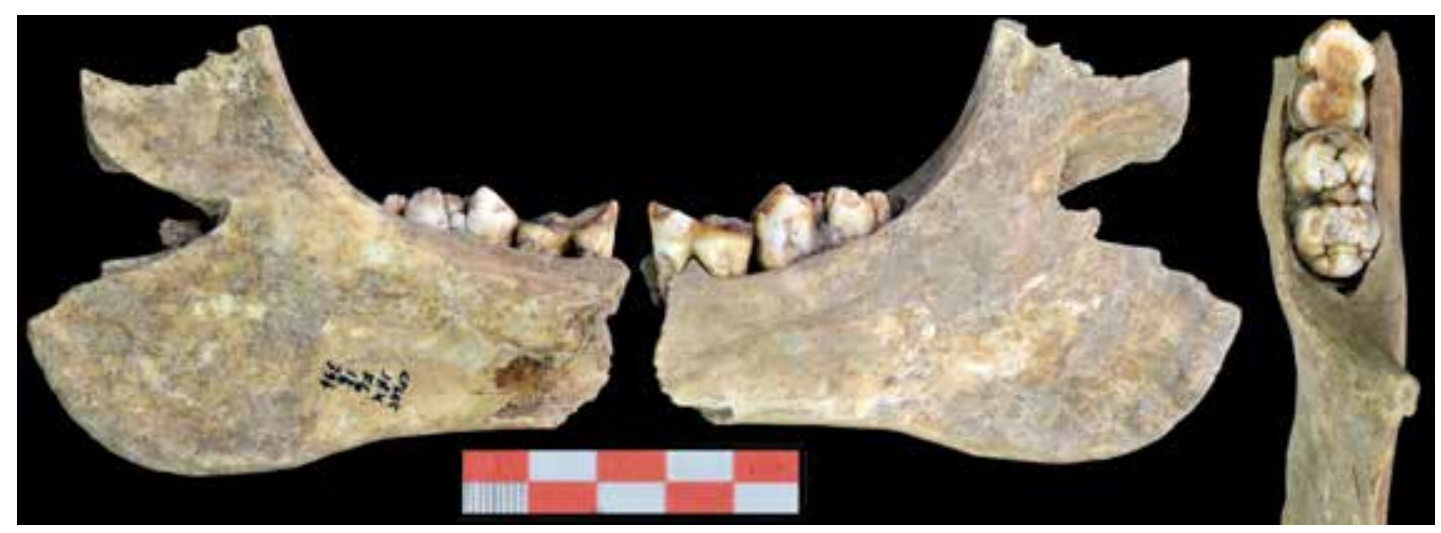

\section{FIGURE 7}

Mandíbula de cerdo seccionada a la altura del primer molar. Normas bucal, lingual y oclusal. Se observa, además, un desgaste anormal de la superficie oclusal en el primer molar. Fotografía: Pablo Castellano-Alonso.

nos parecía, a priori, el más apropiado para este inicio, pues ya se contaba con otros estudios que han abordado este aspecto a través del análisis de elementos de la cultura material (del-Pino-Curbe1o, 2014). Pero hemos de realizar algunas precisiones antes de proseguir. En primer lugar, no se ha efectuado el estudio integral de la Estructura 12, pues solo se dispone del registro óseo procedente de la alcoba Este, excavado en los años 90 del siglo $\mathrm{XX}$, así como de estudios parciales sobre los materiales de importación europea (González-Marrero et al., 2013). En la actualidad, se está acometiendo la documentación arqueológica integral de esta vivienda. También tenemos claro que los datos de nuestro trabajo no pueden extrapolarse a la generalidad del poblado, ni siquiera en lo que se refiere a la segunda fase de su ocupación (siglos XIII-XVI), coetánea a la Estructura 12 aquí analizada.

El primer resultado de extraordinario interés desprendido de este estudio es el concerniente a la composición taxonómica, ya que refleja un hecho hasta el momento prácticamente inédito en la bibliografía arqueozoológica del Archipiélago: la presencia mayoritaria de restos de cerdo en un contexto de cronología prehispánica, con unos porcentajes $(\mathrm{NME}=63 \%)$ muy superiores a los de OC $(\mathrm{NME}=37 \%$ ). Además, dado que la cueva rupestre que alberga el nivel 5 (C.E. II) es claramente anterior a la construcción de la vivienda que la fosiliza (Estructura 12), como indican, entre otras evidencias arqueológicas, tanto la datación realizada como la ausencia de materiales coloniales, podríamos intuir un cambio diacrónico en la preferencia por la explotación de unas especies en favor de otras.
Así, se pasa de unas tasas de suidos muy altas en el nivel 5 (C.E. II) de la cueva (NME=63\%), de época aborigen, hasta los niveles 2-3 de la alcoba Este (NME $=39 \%$ ), asociados al momento de uso de la vivienda erigida a partir de la segunda mitad del siglo XV y ocupada hasta las primeras décadas del XVI.

Para poder valorar en su justa medida la importancia del cerdo en la Estructura 12 de la Cueva Pintada comparamos nuestros resultados con los datos disponibles de otros estudios que presentan el NR o las frecuencias relativas de fauna doméstica. Si nos fijamos en los diez yacimientos de carácter doméstico fuera de la isla de Gran Canaria con datos específicos, todos los autores y autoras destacan un amplio predominio del ganado caprino sobre el porcino. En las cuevas de Los Cabezazos, de Quiquirá y de Don Gaspar en Tenerife, y la de El Tendal en La Palma, se documentan unos porcentajes de suidos mayores de lo normal, pero nunca superando a los caprinos (Diego, 1975; Arco, 1985; Arco et al., 1988; Atoche et al., 1989a; Pais, 1996). En el resto de yacimientos de La Palma (El Rincón y Belmaco) y Tenerife (Arenas-3), así como en el analizado en La Gomera (Cueva F del Barranco de los Polieros) y Lanzarote (El Bebedero y San Marcial del Rubicón) dominan ampliamente los caprinos (Atoche et al. 1989b; Tejera \& Aznar, 1989; Navarro, 1992; Pais, 1996, 2003; Galván et al., 1999).

Fuera de los contextos domésticos, se han desarrollado estudios arqueozoológicos sobre espacios rituales, como por ejemplo las aras de sacrificio de El Hierro (Hernández, 2002) y de La Gomera (Navarro et al., 2000; Alberto et al., 2015) donde el 
predominio del ganado caprino es indiscutible, si bien no consideramos que este tipo de conjuntos sea representativo de las prácticas ganaderas, pues pudo haber una selección de animales o de partes de los mismos para ritos específicos.

Volviendo a la isla de Gran Canaria, existen sitios donde se cumple la premisa de que los pequeños bóvidos dominan con grandes diferencias sobre los suidos (Tabla 11), como por ejemplo en Dunas de Maspalomas (Castellano-Alonso, 2013, 2016), Aguadulce (Martín-Rodríguez et al., 2003a), Risco Chimirique (Martín-Rodríguez et al., 2001; Martín-Rodríguez et al., 2003b), La Puntilla (Arco, 2011) y El Tejar (Ascanio et al., 2004). En los yacimientos de San Antón-la Calle Sol (Velasco \& Alberto, 2003, 2005) y de la Fortaleza de Santa Lucía de Tirajana (Schlueter, 2009), se menciona la superioridad de los caprinos (señalada con dos asteriscos en la Tabla 11) frente a los suidos (un asterisco en la Tabla 11), sin desvelarse los datos exactos. En cambio, en el Lomo Los Melones, T.M. de Telde, los caprinos dominan en el nivel de ocupación de la Estructura 1, mientras que en la Estructura 2 lo hacen los cerdos, estando ambos espacios datados entre los siglos XIV y XV (Castellano-Alonso, 2016; Castellano-Alonso et al., 2016). El yacimiento de La Cerera, en el T.M. de Arucas, del que solo se ha realizado un estudio parcial de los materiales recuperados en la campaña de 2004 (Castellano-Alonso, 2013), tiene 3 fases de ocupa-

\begin{tabular}{|lcccc|}
\hline Yacimiento & $\begin{array}{c}\text { \%R } \\
\text { OC }\end{array}$ & $\begin{array}{c}\text { \%NR } \\
\text { SUS }\end{array}$ & Cronología & Ubicación \\
\hline La Cerera, Fase I & 36 & 64 & XI-XII & Norte \\
\hline La Cerera, Fase II & 26,5 & 73,5 & X-XI & Norte \\
\hline Cueva Pintada (Est.12, Niv. 5) & 37 & 63 & XV & Noroeste \\
\hline Dunas de Maspalomas & 100 & - & VII-XI & Sur \\
\hline La Puntilla (Est. 1, FOI-II) & 78 & 22 & VII-XV & Suroeste \\
\hline La Puntilla (Est. 2, FOI-II) & 87,5 & 12,5 & VII-XVII & Suroeste \\
\hline Aguadulce & 99 & 1 & V-VI & Este \\
\hline L. Los Melones. Est. 1, UEII & 53 & 47 & XIV-XV & Este \\
\hline L. Los Melones. Est. 2, UEII & 42 & 58 & XIV-XV & Este \\
\hline San Antón, Calle-Sol & $* *$ & $*$ & X-XIII & Este \\
\hline La Restinga, E-7 & 65 & 35 & XIII-XIV & Este \\
\hline La Restinga, E-7b & 49 & 51 & XI-XIII & Este \\
\hline Risco Chimirique-I & 80 & 20 & VII & Centro \\
\hline Risco Chimirique-II & 93 & 7 & XI-XIII & Centro \\
\hline El Tejar (Est. 1) & 76 & \multirow{2}{*}{ XIII-XIV } & Centro-NE \\
\hline Fortaleza Santa Lucía & $* *$ & $*$ & XIII & Centro-SE \\
\hline
\end{tabular}

TABLA 11

Porcentajes del NR de caprinos y cerdos en yacimientos de Gran Canaria ordenados según su ubicación. Se debe tener en cuenta que las cronologías son aproximadas, en algunos casos obtenidas sobre carbones sin determinar. ción, destacando la frecuencia elevada de cerdo en las fases I (ss. XI-XII d.C.) y II (ss. X-XI d.C. cal. (del-Pino-Curbelo et al., 2016), aunque la Fase III, la más antigua, no cuenta con muestra suficiente como para proporcionar datos. En la Fase I se localizan materiales foráneos, como vidrio tallado, que permiten afirmar que la ocupación se prolongó al menos hasta el momento de contacto con población europea. La Restinga, en el T.M. de Telde (Alberto et al., 2018), presenta unos valores de suidos del $51 \%$ en la Estructura 7-b, cuya cronología se enmarca entre los siglos XI-XIII d.C. y se ha estudiado cerca del 30\% del material recuperado. Por el contrario, los caprinos dominan en la Estructura 7 del mencionado yacimiento, datado entre los siglos XIII-XIV d.C. (alrededor del 25\% del material recuperado fue analizado).

El análisis conjunto de todos estos yacimientos permite vislumbrar una importancia del cerdo en la sociedad prehispánica de Gran Canaria mucho más destacada de la hasta ahora evidenciada. En particular, los yacimientos de La Cerera (fases I y II), el nivel 5 (C.E. II) de la Estructura 12 de la Cueva Pintada, la Estructura 2 del Lomo Los Melones y la Estructura 7-b de La Restinga, muestran tasas superiores al 50\% del NR. Los dos primeros yacimientos se localizan en la zona Norte de la isla, mientras que los dos últimos se encuentran en el Este. Hasta la fecha, los trabajos preliminares en La Cerera y el más avanzado del Lomo Los Melones eran los únicos del archipiélago que presentaban unos porcentajes de cerdos superiores a los caprinos, pero el caso de La Cerera debe ser tratado con cautela hasta finalizar el análisis global de la muestra recuperada. Queda por determinar si esta significativa presencia en determinados enclaves de la isla dependía de los condicionantes bioclimáticos, ya que en yacimientos ubicados en zonas del centro y del sur insulares los caprinos son las especies que priman con gran diferencia.

Dentro del ganado caprino, se ha podido apreciar un mayor número de cabras que de ovejas en cada contexto y periodo de la muestra de la Estructura 12, evidente a partir del NME (Tabla 6). Ello puede ser indicativo de una explotación preferencial de estos animales por su mayor grado de adaptación al ecosistema existente en Gáldar. La zona costera de este municipio presenta un clima árido, estando su paisaje conformado en determinadas zonas por una vegetación halófilo-costera y por el piso vegetal más bajo, el matorral xerófilo o cardonal-tabaibal, que se extiende hasta los $400 \mathrm{msnm}$. Por encima 
de éste quedaría comprendido el bosque termófilo, compuesto por la palmera canaria, la sabina, el drago y el sauce, principalmente. Los espacios dominados por la laurisilva, hábitat en el que los cerdos encuentran mucho más alimento como las rizomas de helechos, distintas raíces y frutos, pero en el que los caprinos tienen más dificultades, se ubican más hacia el interior, aún dentro del área de influencia del poblado (Pais, 1996; Santana, 2001; Arco \& Rodríguez, 2003; Morales, 2010). Por lo general, las cabras son capaces de digerir forrajes de baja calidad como los que se encuentran en los pisos más bajos descritos, con mayor eficacia que las ovejas y consumen una menor cantidad de agua. Incluso en condiciones climatológicas muy desfavorables, su producción láctea es muy aceptable, lo cual les confiere unas ventajas económicas nada desdeñables (García, 1983; Fernández et al., 2006). Pero el mantener una mayor proporción de cabras podría deberse, quizás, a una mera cuestión cultural, ya fuera por tradición o por un mayor disfrute de sus derivados, tanto primarios (carne, sebo, pieles, tendones y huesos) como secundarios.

El segundo resultado a destacar lo ofrecen los perfiles de mortalidad. El estudio de las fusiones epifisarias y desgastes dentales de los caprinos ha evidenciado el sacrificio regular de todas las cohortes, sugiriendo una gestión ganadera autosuficiente, capaz de generar excedentes y orientada a la explotación de productos secundarios. El estudio del depósito del nivel 5 (C.E. II), con la muestra más abundante, refleja una aparente proporcionalidad entre el sacrificio de individuos jóvenes y subadultos, menores de 4 años, y adultos. Haciendo un balance general, los sacrificios se enmarcan dentro de tres categorías de edad: en primer lugar, los animales adultos, con especial incidencia de aquellos entre 4-6 años; en segundo lugar, individuos neonatos y hasta de 2 meses de edad; y en tercer lugar, ejemplares infantiles y juveniles, de entre 2 y 12 meses de edad. Siguiendo el estudio etnográfico de J. Pais en la isla de La Palma (Pais, 1996), este patrón de sacrificios puede explicarse atendiendo a los procesos de regulación y regeneración de los rebaños. $\mathrm{Al}$ nacer las nuevas crías, los pastores suelen elegir a los miembros que reemplazarán a los individuos desaparecidos, demasiado viejos, poco productivos o que han sufrido algún tipo de percance. Una vez hecho esto, entre los individuos neonatos se seleccionan aquellos que se van a criar con objeto de lograr su engorde y así proporcionar una cantidad de carne mucho mayor y el resto se sacrifica (Pais, 1996; Velasco \& Alberto, 2005).
En el caso de los cerdos observamos la tendencia opuesta, dado que en todos los contextos la casi totalidad de sacrificios se concentra en la cohorte subadulta, integrada por ejemplares de entre 12 y 25 meses, etapa correspondiente con el óptimo cárnico. Este patrón apunta con claridad a una crianza especializada de este ganado, dirigida al engorde para obtener el mayor rendimiento cárnico. Se ha referido que los cerdos modernos alcanzan su masa máxima en torno a los 18 meses de edad (García \& Capote, 1982; Lawrence \& Fowler, 2002), suponiéndose un desarrollo más lento para períodos más antiguos (Wright et al., 2014). Aunque escaso, también se documenta el consumo de lechones, siendo la alcoba Este donde las proporciones son más elevadas.

Poco se ha escrito hasta la fecha sobre la frecuencia y el periodo del año en el que las cerdas daban a luz durante el periodo aborigen de las Islas Canarias. Tal y como indicaba Lauwerier para otros contextos geográficos e históricos (Lauwerier, 1983), las cerdas pueden parir una, dos o tres veces al año, o cinco veces cada dos años, en función de factores biológicos, climáticos y económicos, así como de posibilidades de alimento y los conocimientos técnicos y prácticos de los criadores. Asumiendo que las hembras son fértiles durante todo el año, y que al menos determinados espacios de la zona norte de la isla de Gran Canaria suponían un entorno ecológico propicio para la cría de los cerdos, tanto desde un punto de vista climatológico como de aporte de alimentos (Jiménez et al., 1996; Jiménez, 2009), debemos centrar nuestra atención en los factores económicos y de conocimientos técnicos. En este sentido, nuestros resultados indican que los antiguos canarios fueron capaces de asegurar el mantenimiento de un elevado número de ejemplares hasta alcanzar el óptimo cárnico. Este proceso supone alimentar a un animal por espacio de 12-25 meses, sin obtener ningún rédito hasta el momento mismo del sacrificio. Por esta razón, no resulta desdeñable la hipótesis de que mantuvieran piaras de cerdos nacidos en distintas épocas del año con el objetivo de poder sacrificar aquellos ejemplares con una masa adecuada cuando hubiera mayor demanda de carne, tal como acontecería durante eventos políticos o sociales.

Las fuentes narrativas son instrumentos de gran valor informativo si tratamos de vislumbrar la sociedad canaria del siglo XV, guardando, como también sucede con las fuentes arqueológicas, todas las precauciones necesarias. Relacionado con el tema Archaeofauna 27 (2018): 37-56 
que estamos abordando, en algunos de estos textos se especifica que la población canaria disponía de casas de recreación y pasatiempos, donde se producían banquetes en los que predominaba la carne asada, pero también la había frita y guisada, como se indica por ejemplo en la Crónica Ovetense (Morales, 1978). En las relaciones de Sedeño (Morales, 1978) se habla además de las celebraciones ligadas a las bodas, donde las comidas eran muy abundantes. Estos pueden ser algunos ejemplos de los momentos y espacios en los que habría demanda de más carne y por tanto se realizaran matanzas programadas con antelación o de manera imprevista.

Los datos disponibles de la Estructura 12 no permiten reconocer la procedencia local o de otras zonas de la isla de los animales consumidos en el caserío de la Cueva Pintada. A favor de la primera hipótesis juega la presencia -si bien exigua- de neonatos de caprinos y de cerdos entre los desechos de consumo. Como hemos mencionado, una estrategia para controlar el exceso de animales destinados al engorde sería la matanza de un determinado número en los primeros meses de vida. No podemos, sin embargo, desestimar otra posibilidad que podría resultar igualmente válida: que al menos una parte de los animales proceda de otros parajes, pudiendo haber sido introducidos en el poblado bien como animales vivos o ya como carcasas procesadas. A pesar de las contradicciones que encontramos en las fuentes escritas, todo apunta a pensar que, al menos en los últimos compases del periodo propiamente prehispánico, la jefatura de la isla se hallaba dividida en dos núcleos políticos, gobernados por linajes aristocráticos emparentados, que se han dado en llamar guanartematos (Onrubia, 2003): el guanartemato de Gáldar, que ocupaba las zonas norte, noroeste y oeste de la isla, y el de Telde, cuya influencia parece extenderse al resto del territorio. A partir de algunos textos, como la controvertida crónica atribuida al presunto conquistador Antonio Sedeño (Morales, 1978), tal vez podría plantearse la posibilidad de la existencia de algún tipo de "tributo" entregado por los distintos pueblos a los titulares de estos centros políticos. Si bien en este texto se habla expresamente de la donación de un "diezmo" en grano a las figuras vinculadas a la religión, que se encargaban de la custodia de los graneros colectivos, y se sustentaban de los "frutos" allí almacenados, cabría la posibilidad de que existiera un modo de proceder similar en el caso del ganado, produciéndose entregas de determinadas cabezas al cumplir una edad determinada o en fechas señaladas. La verificación de esta hipótesis pasaría por realizar estudios de isótopos en distintas localidades de la isla, para evaluar la posible movilidad de los ganados. Sin embargo, este tipo de aproximaciones puede tener una serie de dificultades añadidas en el territorio de Canarias. Por un lado, habría que entender si los valores isotópicos a estudiar podrían verse alterados por el carácter volcánico de los sedimentos, y por otro, desconocemos los cambios isotópicos que la vegetación y el agua podrían reflejar entre puntos geográficamente tan próximos.

El último aspecto que queremos reseñar son los datos ofrecidos por la distribución anatómica. En el nivel 5 (C.E. II) se aprecia una considerable acumulación de elementos anatómicos de escaso valor cárnico, especialmente de aquellos procedentes del cráneo. Merece la pena destacar la elevada presencia de dientes incisivos, caninos, premolares y molares, muchos de ellos insertos tanto en las mandíbulas como en los maxilares, sugiriendo que los desplazamientos de este conjunto de restos de fauna habrán sido mínimos. Es decir, se puede considerar una acumulación depositada en contexto primario. ¿Cómo interpretar tal abundancia de elementos craneales? En coincidencia con lo que puede deducirse de las observaciones arqueológicas, nos parece factible plantear dos hipótesis de trabajo: a) que correspondan a desechos generados por acciones de carnicería primaria de caprinos y de suidos realizados junto a esta cavidad en algún momento anterior a la construcción de la Estructura 12 ; b) que se relacionen con el consumo preferencial de esta porción anatómica por parte de quienes usaron esa cavidad.

El patrón de fracturación referido en las mandíbulas de cerdo consistente en la rotura del cuerpo mandibular a la altura del primer molar con el fin de aprovechar el tuétano contenido en su interior sugiere que las cabezas, una vez separadas del resto del cuerpo, sufrieron un tratamiento secundario. La abundancia también de cráneos de caprinos, la ausencia significativa en este nivel de otros elementos anatómicos del esqueleto axial y apendicular, así como la falta de referencias en las fuentes etnográficas a una potencial preferencia por el consumo de cabezas entre determinados grupos sociales, nos inclina a favorecer la primera hipótesis. Las evidencias recabadas son compatibles con los despojos de la actividad carnicera.

La génesis del nivel 4 (C.E. II) parece encontrarse, al menos parcialmente, en la propia remo- 
vilización del nivel 5 (C.E. II) y en el desmantelamiento, y ulterior deposición durante toda la fase de formación de ese depósito, del nivel 3 (C.E. II) de la alcoba Este. Otra posibilidad es que una parte de los materiales de este nivel arqueosedimentario proceda de arrastres no intencionales que se han documentado en otros sectores y en niveles superiores del poblado. El número menor de restos, la representación de todas las categorías anatómicas y el descenso en la frecuencia de elementos craneales reflejan el origen mixto de esta acumulación.

Por último, los escasos materiales recuperados de la alcoba Este también forman parte de un contexto secundario, procedente del nivel de arruinamiento de los muros y del techo de la estructura (C.E. II, nivel 2) así como del suelo artificial de preparación de la misma (C.E. II, nivel 3). La recuperación de elementos de los cuartos delantero y trasero nos sugiere tratarse de desecho de consumo doméstico.

\section{CONCLUSIONES}

El conjunto faunístico de la Estructura 12 resulta de excepcional interés dentro de la arqueozoología de Canarias, especialmente la muestra recuperada en el nivel 5 (C.E. II) de la cámara rupestre. No solo por el número de restos determinados $(\mathrm{NISP}=1730)$ sino por la frecuencia elevada de cerdo $(\mathrm{NME}=63 \%)$, para lo que suele ser habitual en el archipiélago. La importancia del ganado porcino a nivel dietético y económico no aparece reflejada en las fuentes documentales, lo que corrobora el interés de los análisis arqueofaunísticos como método analítico que proporciona evidencias directas sobre hábitos de consumo y prácticas culturales ignoradas por otros registros históricos. Hemos podido comprobar cómo el ganado caprino ha sido sacrificado en todas las cohortes de edad, existiendo una aparente proporcionalidad entre el grupo conformado por los individuos neonatos, infantiles y subadultos con el de los adultos. Por el contrario, los cerdos se sacrificaban casi exclusivamente cuando habían alcanzado su óptimo cárnico, lo que demuestra una gestión especializada de este ganado. Por otra parte, resulta muy interesante que no se haya documentado una alteración en la composición de la cabaña ganadera en los momentos postconquista, cuando en el contexto de esta estructura sí que existen otros elementos importados.
Esta circunstancia invita a reflexionar sobre la naturaleza y la incidencia real de las relaciones que se establecen entre indígenas y el contingente conquistador durante los primeros estadios de la nueva sociedad colonial.

¿Nos encontramos ante la constatación de que el cerdo tuvo un peso mayor en la alimentación de los antiguos habitantes de Gran Canaria del que tradicionalmente se creía? ¿O se trata de una situación anómala asociada a eventos concretos? ¿Se produjo un cambio en las preferencias culinarias a favor de los caprinos tras la llegada de los colonizadores, como parece sugerir el aumento del consumo de ovejas y cabras en las pequeñas muestras de los niveles 4,3 y 2 (C.E. II)? ¿O el cambio de tendencia refleja apenas la disparidad de los orígenes de las muestras analizadas? Aunque por el momento carecemos de respuestas definitivas, parece empezar a desvelarse el papel destacado del cerdo en la economía y la dieta aborigen de, al menos, ciertos lugares de la isla de Gran Canaria que solo con más investigación podrá confirmarse.

\section{AGRADECIMIENTOS}

La realización de este artículo ha sido posible gracias a la financiación del Ministerio de Educación y Deporte por medio de una Beca predoctoral de Formación del Profesorado Universitario (FPU1135). Asimismo, este trabajo se enmarca en el proyecto de investigación HAR2017-83025-P del Ministerio de Economía, Industria y Competitividad.

Queríamos expresar nuestro agradecimiento a Elena López-Romero González de la Aleja y Esther Checa Gómez, del Instituto de Historia de Madrid, por su apoyo en diversas fases de los estudios.

\section{REFERENCIAS}

Alberto, V.; Navarro, J.F. \& Castellano-Alonso, P. 2015: Animales y ritual. Los registros fáunicos de las aras de sacrificio del Alto de Garajonay (La Gomera, Islas Canarias). Zephyrus 76: 159-179.

https://doi.org/10.14201/zephyrus201576159179

Alberto, V.; Moreno, M.; Alamón, M.; Suárez, I. \& Mendoza, F. 2018: Estudio zooarqueológico de La Restinga (Gran Canaria). Datos para la definición de 
un modelo productivo. En XXII Coloquio de Historia Canario-Americana (2016). Las Palmas de Gran Canaria: Cabildo de Gran Canaria. En prensa.

Arco, C. DEL 1985: Excavaciones en la Cueva de Don Gaspar (Icod de los Vinos, Tenerife). Noticiario Arqueológico Hispánico 20: 257-377.

- 2011: En el lugar de Mogán. Estudios arqueológicos en el Poblado de la Puntilla (Barranquillo de los Gatos, Playa de Mogán, Gran Canaria). Canarias Arqueológica 19(Anejo I): 1-202.

Arco, C. Del \& Rodríguez, O. 2003: Las Comunidades Vegetales de Gran Canaria. En: Rodríguez, O. (ed.): Apuntes sobre flora y vegetación de Gran Canaria: 71-134. Cabildo de Gran Canaria, Las Palmas de Gran Canaria.

Arco, C. Del; Toro, A. \& Meco, J. 1988: Mammal remains in prehistoric sites in the Canary Islands. Deserts: evolution passée et future $=$ past and future evolution: 7-16.

Ascanio, A.; Mendoza, F.; Moreno, M. \& SuÁrez, I. 2004: Intervención arqueológica en El Tejar (Santa Brígida, Gran Canaria). Primeros resultados. En: XV Coloquio de Historia Canario-Americana: 2131-2146. Cabildo de Gran Canaria, Las Palmas de Gran Canaria.

Aтоche, P. 2003: Fenómenos de intensificación económica y degradación medioambiental en la protohistoria canaria. Zephyrus 56: 183-206.

Atoche, P.; Lorenzo, M.J. \& Ramírez, M.Á. 1989a: Trabajos arqueológicos en la cueva de Quiquirá (La Orotava, Tenerife). Cabildo Insular, Aula de Cultura de Tenerife.

Atoche, P.; Rodríguez, M.D. \& Ramírez, M.Á. 1989b: El yacimiento arqueológico de «El Bebedero» (Teguise, Lanzarote): resultados de la primera campaña de excavaciones. (Lanzarote). Universidad de La Laguna, Secretariado de Publicaciones. Ayuntamiento de Teguise.

BARONE, R. 1976: Anatomie comparée des mammifères domestiques. Vigot, Paris.

Blasco, M.F. 1992: Tafonomía y Prehistoria. Métodos y procedimientos de investigación. Dpto. Ciencias de la Antigüedad (Prehistoria), Universidad de Zaragoza, Zaragoza.

Boessneck, J.; Müller, H. \& Teichert, M. 1964: Osteologische Unterscheidungsmerkmale zwischen Schaf (Ovis aries Linne) und Zeige (Capra hircus Linne). Kuhn Archiv 78: 1-129.

Castellano-Alonso, P. 2013: Iniciación al estudio arqueozoológico de los recursos faunísticos de origen terrestre en la isla de Gran Canaria en época preeuropea y colonial (siglos IV al XVI). Tesis de Máster. Universidad de Las Palmas de Gran Canaria.
- 2016: Zooarqueología. Una forma de contribución al estudio de los procesos de colonización en una isla oceánica. El ejemplo de Gran Canaria (Islas Canarias). In: Coelho, I.P.; Torres, J.B.; Gil, L.S. \& Ramos, T. (eds.): Entre ciência e cultura: Da interdisciplinaridade à transversalidade da arqueologia. Actas das VIII Jornadas de Jovens em Investigação Arqueológica: 285-290. CHAM-FCSH/UNL-UAç e IEM-FCSH/UNL. Lisboa.

Castellano-Alonso, P.; Moreno-García, M.; Alberto, V.; Rodríguez-Rodríguez, A.; Arencibia, A. \& Blanco, D. 2016: El Lomo Los Melones (Telde). Explotación prehispánica del ganado doméstico en un enclave costero. En XXI Coloquio de Historia Canario-Americana: 1-14. Cabildo de Gran Canaria, Las Palmas de Gran Canaria.

Del-Pino-Curbelo, M. 2014: Caracterización de la cerámica elaborada a mano en Gran Canaria prehispánica. Tesis Doctoral inédita. Universidad de Las Palmas de Gran Canaria, Las Palmas de Gran Canaria.

Del-Pino-Curbelo, M.; Rodríguez-Rodríguez, A.; BuXeda, J.; Mangas, J.; Day, P.M.; González, P. \& MoRENO, M.A. 2016: Las cerámicas aborígenes de Gran Canaria (Islas Canarias) a través del yacimiento de La Cerera: materias primas, tecnología y función. Trabajos de Prehistoria 73(1): 90-114. https://doi. org/10.3989/tp.2016.12165

Diego, L. 1975: La Cueva de los Cabezazos en el Barranco del Agua de Dios, (Tegueste, Tenerife). Noticiario Arqueológico Hispánico 4: 289-335.

Fernández, C.; MAtA, C. \& BACHA, F. 2006: Alimentación caprina y calidad de la leche. Ganadería 41: 4247.

Fontugne, M.; Hatté, C.; NúÑez, M.A.; Olmo, S.; ONRubia, J.; García, A. \& Soler, V. 1999: Parque arqueológico Cueva Pintada (Gáldar, Gran Canaria): Programa de intervenciones e investigaciones arqueológicas. Avance de los trabajos efectuados entre los años 1995-1997. Investigaciones arqueológicas 6 : 489-561.

Fregel, R.; Gomes, V.; Gusmão, L.; González, A.M.; Cabrera, V.M.; Amorim, A. \& Larruga, J.M. 2009: Demographic history of Canary Islands male gene-pool: replacement of native lineages by European. BMC Evolutionary Biology 9(1): 181-195. https://doi. org/10.1186/1471-2148-9-181

Galván, B.; Hernández, C.M.; Velasco, J.; Alberto, V.; Borges, E.; Barro, A. \& Larraz Mora, A. 1999: Orígenes de Buenavista del Norte: de los primeros pobladores a los inicios de la colonización europea. Ayuntamiento de Buenavista del Norte.

GARCÍA, D.R.M. 1983: La cabra y los alimentos. En: Hernández, J.M. (ed.): Manual sobre cabras: 53-94. 
Ministerio de Agricultura, Pesca y Alimentación, Madrid.

García, M. \& CAPOTE, J. 1982: El cerdo negro canario. Excmo. Cabildo Insular de La Palma.

González-Marrero, M.D.C.; SÁenz, J.I. \& Onrubia, J. 2013: Inventario de los hallazgos monetarios de la Cueva Pintada (Gáldar, Gran Canaria). El numerario hispano-luso de los siglos XV y XVI. Anuario de estudios atlánticos 59: 605-630.

Grant, A. 1982: The use of tooth wear as a guide to the age of domestic ungulates. In: Wilson, B.; Grigson, C. \& Payne, S. (eds.): Ageing and sexing animal bones from archaeological sites: 91-108. B.A.R. (British Series) 109. Oxford.

GraYson, D.K. 1984: Quantitative zooarchaeology: Topics in the analysis of archaeological faunas. Academic Press, New York.

https://doi.org/10.1016/0277-3791(85)90008-3

Hernández, M.S. 2002: El Julan. Dirección general de Patrimonio Histórico.

JimÉNEZ, A.M. 2009: Análisis territorial. En: González, P.; Moreno, M.A. \& Jiménez, A.M. (eds.): El Yacimiento arqueológico de La Cerera. Un modelo de ocupación en la isla de Gran Canaria: 61-92. Cabildo de Gran Canaria, Cultura, Patrimonio Histórico, Gran Canaria.

JiméneZ, A. M.; GonZÁlez, P. \& ZAMORA, J. M. 1996: El poblamiento prehistórico en la comarca de Arucas: Aproximación a un estudio del territorio. Tabona IX: 125-147.

LAUWERIER, R.C.G.M. 1983: Pigs, piglets and determining the season of slaughtering. Journal of Archaeological Science 10: 483-488.

https://doi.org/10.1016/0305-4403(83)90063-8

LAwrence, T.L.J. \& Fowler, V.R. 2002: Growth of Farm Animals (Second). CABI Publishing.

Legge, A.J. 2013: 'Practice with Science': Molar Tooth Eruption Ages in Domestic, Feral and Wild Pigs (Sus scrofa). International Journal of Osteoarchaeology: $1-18$.

Lemoine, X.; Zeder, M.A.; Bishop, K.J. \& Ruffolo, S.J. 2014: A new system for computing long-bone fusion age profiles in Sus scrofa. Journal of Archaeological Science 47: 179-193. https://doi.org/10.1016/j. jas.2014.12.017

Lyman, R.L. 1994: Vertebrate Taphonomy. Cambridge University Press, Cambridge.

Martín-Rodríguez, E.; Velasco, J. \& Alberto, V. 2001: Excavaciones arqueológicas en Risco Chimirique, (Tejeda, Gran Canaria). Tabona 10: 251-354.

Martín, C.; Onrubia, J. \& SÁenz, J.I. 1994: Trabajos en el Parque Arqueológico de la Cueva Pintada de Gál- dar, Gran Canaria. Anuario de Estudios Atlánticos 40: 17-116.

- 1996: Trabajos en el Parque Arqueológico de la Cueva Pintada de Gáldar, Gran Canaria. Avance de las intervenciones realizadas en 1993. Anuario de Estudios Atlánticos 42: 17-96.

Martín-Rodríguez, E.; Velasco, J. \& Alberto, V. 2003a: Excavaciones arqueológicas en Aguadulce, Tejeda (Gran Canaria). Investigaciones arqueológicas 7: 143-250.

Martín-Rodríguez, E.; Velasco, J.; Alberto, V. \& RoDRÍGUEZ-RodrígueZ, A. 2003b: Vivir y morir en Risco Chimirique. Investigaciones arqueológicas en la cuenca de Tejeda (Gran Canaria). Anuario de Estudios Atlánticos 49: 163-248.

Morales, F. 1978: Canarias: Crónicas de su conquista. El Museo Canario, Ayuntamiento de Las Palmas.

Morales, J. 2010: El uso de las plantas en la prehistoria de Gran Canaria: alimentación, agricultura y ecología. Monografía Cueva Pintada I. Cabildo Insular de Gran Canaria.

Morales, J.; Navarro, J.F. \& Rodríguez-Rodríguez, A. 2009: Plant offerings to the Gods: seed remains from a pre-hispanic sacrificial altar in La Gomera island. In: Fahmy, K.; Kahlheber, A.G. \& D’Andrea, S. (eds.): Windows on the African Past. Current approaches to African Archaeobotany. Proceeding to the $6^{\text {th }}$ International Workshop on Africa Archaeobotany: 67-78. Frankfurt-Main, Africa Magna Verlag, El Cairo.

Moreno-García, M.; Orton, C. \& Rackham, J. 1996: A New Statistical Tool for Comparing Animal Bone Assemblages. Journal of Archaeological Science 23: 437-453. https://doi.org/10.1006/jasc.1996.0039

Navarro, J.F. 1992: Los gomeros, una prehistoria insular. Dirección General de Patrimonio Histórico, Viceconsejería de Cultura y Deportes del Gobierno de Canarias, Tenerife.

Navarro, J.F.; Hernández, C.m.; Alberto, V.; Borges, E.; Barro, A. \& Hernández, J.C. 2000: Aras de sacrificio y grabados rupestres en el Lomo del Piquillo (isla de La Gomera). Anuario del Instituto de Estudios Canarios 45: 317-340.

O'Connor, T.P. 1988: Bones from the General Accident Site, Tanner Row (Vol. 15). Council for British Archaeology. London.

- 2003: The Analysis of Urban Animal Bone Assemblages: A Handbook for Archaeologists. Archaeology of York.

ONRUBIA, J. 2003: La Isla de los Guanartemes. Territorio, sociedad y poder en la Gran Canaria indígena (siglos XIV-XV). Cabildo de Gran Canaria, Las Palmas de Gran Canaria. 
- 2012: El caserío de la Cueva Pintada y la arquitectura doméstica prehispánica de Gran Canaria. Materialidades y materiales. Cabildo de Lanzarote.

OnRubia, J.; Rodríguez, C.G.; SÁEnZ, J.I.; GonZÁlez, M. Del C. \& Olmo, S. 1998: Los materiales arqueológicos «históricos» de la Cueva Pintada de Gáldar. Una primera aproximación al contexto de las series coloniales bajomedievales y modernas (s. XV-XVI). XII Coloquio de Historia canario-americana: 643-674.

PAIS, F.J. 1996: La economía de producción en la prehistoria de la isla de La Palma: la ganadería. Direccion General de Patrimonio Historico, Viceconsejeria de Cultura y Deportes, Gobierno de Canarias.

- 2003: Belmaco y el bando prehispánico de Tigalate. Zoras 5-28.

PAYNE, S. 1973: Kill-off patterns in sheep and goats: The mandibles from Aşvan Kale. Anatolian Studies 23: 281-303.

- 1987: Reference codes for wear states in mandibular teeth of young sheep, Ovis, and goats, Capra. Journal of Archaeological Science 14: 609-614.

Pérez, M. 1992: Marcas de carnicería, fracturas intencionadas y mordeduras de carnívoros en huesos Prehistóricos del Mediterráneo Español. Colección Patrimonio. Instituto de Cultura «Juan-Gil Albert».

Rodríguez, C.G. 1996: La pesca entre los Canarios, Guanches y Auaritas. Las ictiofaunas arqueológicas del Archipiélago Canario. Cabildo Insular de Gran Canaria, Las Palmas de Gran Canaria.

Rodríguez, C.G.; Alberto, V.; Rodríguez-RodríGuez, A. \& Galindo, A. 2008: Escamas y cuernos : a propósito de asociaciones insólitas en el yacimiento del Lomo de Los Melones (Telde, Gran Canaria). In: Béarez, P.; Grouard, S. \& Clavel, B. (eds.): Archéologie du poisson: 30 ans d'archéo-ichtyologie au CNRS: 411-424. APDCA, Antibes.

Santana, A. 2001: Evolución del paisaje de Gran Canaria (siglos XV-XIX). Cabildo de Gran Canaria, Las Palmas de Gran Canaria.

Schlueter, R. 2009: La Fortaleza de Santa Lucía de Tirajana. Investigación arqueológica. Boletín Millares Carló 28: 31-68.
Schmid, E. 1972: Atlas of animal bones. For prehistorians, archaeologists and Quaternary geologists. Elsevier Pub. Co., Amsterdam.

Secher, B.; Fregel, R.; Larruga, J.m.; Cabrera, V.M.; Endicott, P.; Pestano, J.J. \& GonzÁlez, A.M. 2014: The history of the North African mitochondrial DNA haplogroup U6 gene flow into the African, Eurasian and American continents. BMC Evolutionary Biology 14(1): 109.

https://doi.org/10.1186/1471-2148-14-109

SEETAH, K. 2006: Butchery as an Analytical Tool: A Comparative Study of the Romano-British and Medieval Periods. Cambridge University Press, Cambridge.

Silver, I.A. 1969: The Ageing of Domestic Animals. In: Brothwell, D.R.; Higgs, E. \& Clark, G. (eds.): Science In Archaeology: A Survey Of Progress and research: 283-302. Thames and Hudson, London.

Tejera, A. \& Aznar, E. 1989: El asentamiento franco-normando de «San Marcial del Rubicón» (Yaiza, Lanzarote). Un modelo de arqueología de contacto. Ayuntamiento de Yaiza, Lanzarote.

Velasco, J. \& Alberto, V. 2003: Excavaciones arqueológicas en la Plaza de San Antón. Agüimes (Gran Canaria). Investigaciones arqueológicas 7: 39-142.

- 2005: Donde habita la historia, La población prehispánica de Agüimes y su territorio, Ayuntamiento de la Villa de Agüimes. Ayuntamiento de la Villa de Agüimes, Agüimes (Gran Canaria).

Wright, E.; Viner-Daniels, S.; Parker, M. \& AlbareLLA, U. 2014: Age and season of pig slaughter at Late Neolithic Durrington Walls (Wiltshire, UK) as detected through a new system for recording tooth wear. Journal of Archaeological Science 52: 497-514. https://doi.org/10.1016/j.jas.2014.09.009

ZEDER, M.A. 2006: Reconciling rates of long bone fusion and tooth eruption and wear in sheep (Ovis) and goat (Capra). In: Ruscillo, D. (ed.): Recent advances in ageing and sexing animal bones: 87-118. Oxbow Books, Oxford.

ZeunER, F.E. 1959: Some domesticated animals from the prehistoric site of Guayadeque, Gran Canaria. El Museo Canario 19: 31-40. 
